\title{
Nietzsche et le relativisme
}

Paolo Stellino e Olivier Tinland (Org.) Nietzsche et le relativisme. Bruxelles: Éditions OUSIA, 2019. $298 p$

\section{Eduardo Nasser ${ }^{\mathrm{I}}$}

Relativismo não constitui realmente uma corrente ou escola filosófica. E não obstante prestigiados pensadores, como Galileu ou Comte, falarem em princípio da relatividade ou relativo, com um sólido lastro teórico, o termo é muito frequentemente utilizado no ambiente intelectual contemporâneo com a intenção de desmoralizar ou expor falhas latentes de sistemas e doutrinas. Contudo, a fim de enfrentar desafios de nosso tempo, como inclusão social e cultural, é também preciso destacar a emergência de um interesse renovado pelo relativismo, agora movido pela convicção de que o conceito dispõe de uma gama de frutíferos e pouco conhecidos significados que passam ao largo da percepção vulgar, como vem revelando, especialmente, Maria Baghramian.

É no interior desse cenário filosoficamente mais estimulante que Nietzsche et le relativisme é concebido. Organizado por Paolo Stellino e Olivier Tinland, e dividido em três partes, o livro consiste na reunião de artigos apresentados por reputados estudiosos no colóquio internacional com título homônimo, realizado em 2016 na Université Paul Valéry Montpellier III. De forma geral, o propósito é confrontar a atribuição largamente difundida, de viés injurioso, de relativismo ao pensamento nietzschiano, sem, contudo, deixar de examinar possíveis contribuições de Nietzsche para uma melhor compreensão dos debates mais atilados sobre o tema (e vice-versa).

Redigido por Olivier Tinland, o texto introdutório confere estruturação ao livro. Seguindo a linha dos estudos mais recentes sobre relativismo, Tinland polemiza com as visões trivializadas de modo a evidenciar a complexa teia de conceitos que enseja a adequada interrogação de teses relativistas. "Simplificando ao extremo, pode-se distinguir três maneiras de caracterizá-las, segundo o objeto de relativização, o contexto de relativização, e o modo de relativização" (p. 17). E esses domínios estão sujeitos a divisões e subdivisões: os objetos relativizáveis estão separados em campos de saber (cognitivo, moral, jurídico, político, estético, religioso, etc.) que, por sua vez, possuem ramificações internas (relativismo cognitivo, por exemplo, pode se fragmentar em relativismo epistêmico, alético, racional e conceitual); os contextos de relativização dividem-se em subjetivo e cultural e/ou histórico; os modos de relativismo, atinentes aos tipos de enunciação, distinguem-se pelo enfoque moderado e forte, e pelas enunciações relativistas mesmas, que podem ser restrita (ou de primeira ordem) e total (ou de segunda ordem).

De posse desses instrumentos conceituais, os textos tangenciam pelo menos três objetos de relativização (cognitivo, moral e estético), oferecendo apreciações nem sempre congruentes sobre o contexto e o modo de relativização constatáveis em Nietzsche.

${ }^{\text {I }}$ Doutor em Filosofia pela Universidade de São Paulo e pela Ernst-Moritz-Arndt-Universität Greifswald. Professor na Universidade Federal do ABC. eduardo.nasser@philosophie.uni-freiburg.de. 
No decurso do livro, é manifesta certa prevalência de discussões de cunho epistemológico. Englobam a primeira e segunda parte, e são abalizadas por duas linhas de leitura: (i) Nietzsche enquanto um relativista antirrealista, filiado a Kant e ao neokantismo, que radicaliza a modernidade, pavimentando o caminho para o pensamento pós-moderno; (ii) Nietzsche como um relativista realista que promove uma reforma da ontologia substancialista.

A primeira propensão interpretativa pode ser observada nos trabalhos de Helmut Heit, João Constâncio, Luca Lupo e Pietro Gori. No artigo que inicia o livro, "Nietzsche et « le relativisme épistémique »", Heit almeja mostrar de que modo é possível enxergar em Nietzsche um relativismo epistêmico oriundo de sua frequentação de autores ligados à tradição kantiana. Não obstante a irrelevância do termo relativismo para o filósofo - cuja única ocorrência está localizada na terceira Consideração extemporânea -, e apesar de seu desinteresse por debates mais técnicos sobre epistemologia, é razoável afirmar que "Nietzsche propõe uma versão específica do relativismo, entendido como virtude epistêmica" (p. 41). Após travar contato com Schopenhauer e, sobretudo, Lange, ele desenvolve uma teoria do conhecimento construtivista, movido pelo objetivo mais audacioso de delinear condições para a elevação da cultura. Em " "La vérité relative ». Remarques sur la négation langéenne et postkantienne de la vérité absolue chez Nietzsche”, Constâncio propõe demonstrar que "desde o início, e em numerosas passagens decisivas de seus escritos, Nietzsche subscreve uma concepção de « verdade » que Friedrich Albert Lange retirou de sua leitura da Crítica da razão pura de Kant, a saber, a concepção de « verdade relativa »" (p. 69). Guiando-se por cinco teses basilares daquilo que denomina de póskantismo de Nietzsche (1- caráter transcendental das categorias; 2- mundo estruturado por conceitos e juízos; 3- incognoscibilidade da coisa-em-si; 4- rejeição da verdade no sentido metafísico; 5- impossibilidade da metafísica após Kant), conta apontar de que forma a filosofia nietzschiana está alinhada ao neokantismo naturalista e psicologista de Lange, culminando na concepção de verdade relativa, restringida à experiência, e emancipada de qualquer finalidade prescritiva. Para Lupo, em "Pour une généalogie du relativisme nietzschéen: Schopenhauer", é "no quadro de uma triangulação com Kant e Schopenhauer que se pode identificar uma possível inclinação do pensamento nietzschiano em direção a posições relativistas" (p. 126). Nietzsche utiliza o termo Relativismus na terceira Consideração extemporânea tendo em conta os impasses éticos e existenciais decorrentes da interdição kantiana e schopenhaueriana do acesso epistêmico à verdade absoluta. Por fim, Gori, em "Le pragmatisme et la pensée perspectiviste: des programmes comportementaux pour faire face au relativisme", entende que Nietzsche, assim como William James, redefine o significado da verdade - que passa, então, a possuir valor operatório, condizente com um tipo de relativismo -, à medida que se ampara nos resultados da epistemologia moderna. Antirrealista, Nietzsche deve ser acolhido como um representante do fenomenalismo que, por seu turno, "se apresenta como um desenvolvimento do kantismo no sentido antimetafísico” (p. 158).

Num outro extremo, deparamo-nos com as abordagens de Yannick Souladié e Dorian Astor. Em "Un scepticisme de la force contre le relativisme", Souladié traz à baila um Nietzsche envolvido com uma forma branda de relativismo (conhecimento condicionado pela educação, alimentação, saúde, etc.) que não se dedica a anular o valor do conhecimento ou "a possibilidade de um conhecimento autêntico, de uma "verdade »" (p. 95). O perspectivismo nietzschiano não incorre na defesa da igualização alética das perspectivas que, a propósito, deve ser tratada como um sinal de declínio -, pois vislumbra a vontade de potência enquanto referente último. Com efeito, o nível do conhecimento exprime uma forma mais superficial de relativismo que é antecedido por uma ontologia relacional: "a 
vontade de potência apreendida em seu interior, fora de toda perspectiva relativa (exterior), é relação" (p. 97). Essa subsunção da epistemologia à ontologia é também aventada por Astor em "Relativisme ou relationnisme? Le concept de réalité chez Nietzsche et Whitehead". Ao propor uma comparação oportuna entre as concepções de realidade em Nietzsche e Whitehead, Astor pretende exibir de que maneira esses filósofos, em oposição à atitude preponderante na ciência e na metafísica, estão empenhados na defesa de uma realidade relativa; consiste numa "ontologia da relação fundada sobre o caráter processual do Ser, quer dizer, do Devir" (p. 172).

A tendência predominante nas discussões epistêmicas se estende para os artigos que se ocupam do relativismo ético e estético em Nietzsche; reproduz-se a disputa entre realismo e antirrealismo no campo dos valores. Contudo, o problema adquire uma feição manifestamente distinta do quadro apresentado acima. Trata-se, fundamentalmente, de aclarar se Nietzsche suprime total ou parcialmente o relativismo quando se serve de expedientes realistas para efetuar uma crítica dos valores

Essa segunda espécie de problematização é preparada pelo texto de Scarlett Marton, "De Foucault à Nietzsche: pluralité d'interprétations et importance des critères". A proposta de Marton é defender a tese de que Foucault imprime uma deformação no pensamento nietzschiano quando nele reconhece o marco de uma nova hermenêutica. Para Foucault, Nietzsche não estaria preocupado em inquirir o significado, mantendo-se na superfície das interpretações. Visto por este prisma, somos levados à enganosa suposição de que Nietzsche promove uma equivalência de interpretações, ou um relativismo, quando, a bem da verdade, a sua meta é acomodar criticamente as interpretações em disposições hierárquicas; mediante a eleição de um critério - a vida ou a constante luta de forças -, pretende-se entabular um processo judicativo com a finalidade de apartar boas e más interpretações. $\mathrm{O}$ critério de avaliação deveria ser fixo, apesar de exprimir o vir-a-ser, e transcendente ao nível interpretativo (e, se assim é, imune aos relativismos identificados nos debates epistêmicos?). Em razão de não ter considerado esse intento mais genuíno que Foucault enseja a introdução de "um certo relativismo na filosofia nietzschiana" (p. 225). O desacordo entre o caráter inclusivo do relativismo e o intuito hierarquizante de Nietzsche é também tratado por Isabelle Wienand e Janske Hermens em "Nietzsche et le relativisme: la conception nietzschéenne de la santé". Inserindo-se no sinuoso terreno da filosofia da medicina, o artigo coloca a hipótese de que "a concepção nietzschiana de saúde ilustra de maneira eloquente a posição nuançada ante a questão do relativismo" (p. 244). Malgrado ser um relativista ontológico, visto que se recusa a oferecer uma definição de saúde, Nietzsche não pode ser designado um relativista axiológico. Quando alude à grande saúde, ele admite que se trata de um estado subordinado ao vir-a-ser, sem, no entanto, deixar de se servir do conceito com pretensões avaliativas e normativas. Ainda que os autores não considerem ser um resultado inconsequente, assinalam que "Nietzsche defende duas posições diferentes ou mesmo contrárias" (p. 245). Na mesma esteira, Paolo Stellino, em "Projectivisme et relativisme moral chez Nietzsche", considera que Nietzsche apoia um tipo de relativismo moderado na esfera dos valores; a filosofia nietzschiana pode ser aproximada de um projetivismo moral sem redundar num relativismo total. Beneficiando-se de recursos da ética contemporânea, Stellino salienta que apesar de ser um relativista moral descritivo, Nietzsche seguramente não pode ser chamado de um relativista moral meta-ético - pois exige um critério de avaliação dos valores extrínseco às perspectivas - ou um relativista moral normativo - pois estimula que o indivíduo crie a sua própria tábua de valores. Destarte, não se pode acolher “o perspectivismo moral nietzschiano no sentido de um relativismo radical" (p. 275). Contestando igualmente a atribuição precipitada de relativismo a Nietzsche, mas no âmbito 
da estética, temos o artigo de Maria João Mayer Branco, que encerra o livro, "La tâche du joueur. Jeu et crise des valeurs chez Nietzsche". Branco revela que o concepção nietzschiana de jogo, subtraída de valor e de incumbências prescritivas, "suspende os efeitos da relativização geral dos critérios de validade que regulam, não somente a criação artística, mas a totalidade da vida humana até a modernidade" (p. 278). Atento aos perigos produzidos pela autonomização da arte na modernidade, Nietzsche fala em jogo, uma concepção autorreferida que viabiliza, tanto para a arte, como também para a filosofia, a criação do novo.

Como foi possível constatar, a virtude de Nietzsche et le relativisme é fornecer um mapeamento escrupuloso dos desafios que cercam a compreensão da natureza e do alcance do relativismo nietzschiano e, no limite, indagar se de fato é legítimo classificar Nietzsche como um filósofo relativista. 